\title{
Materials \& low carbon energy production
}

\section{Opinion}

The Portuguese Materials Society is member of the Federation of European Materials Societies and has several Divisions, among other the Division of Materials \& Energy. This Society (SPM) has a journal called Science and Technology of Materials and also a Newsletter. Over the years several papers have been published in the field of energy materials. SPM also organizes technical and scientific events where these matters are discussed. Materials are needed for low carbon energy production technologies, namely for renewable energy technologies and systems, but the production of these materials can also use these new energy production technologies for a better and sustainable processing. One good example of this is related to cork (see e,g, L. Gil, Solar energy and cork: A binomial of the future, Science \& Technology of Materials, vol. 30, No. 2, 2018, pp. 80-86) . In this field several solar energy application possibilities in forestry and industrial processes are considered, and the use of different cork derived products in several solar energy technologies and applications is also assessed. So cork is a sector were solar energy may be used in various ways and cork material can be a component in various solar energy systems/devices. This type of analysis could also be carried out for several other materials production and renewable energy production systems. It would be interesting to have an approach like this, done by several experts in the several domains of materials and low carbon energy production technologies. Sustainability is now not only a key word but also a key concept in every issue of our life. So, in the materials field, the use of natural and sustainable materials is a must. Having in mind the relation between materials and low carbon energy production, a lot of R\&D work has been carried out. Only as a way of example, in this field see e.g. R.C. Pullar, L. Gil, F.A.C. Oliveira, Biomimetic cork-based ecoceramics for hydrogen generation using concentrated solar energy, Science \& Technology of Materials, vol. 28, No. 1, 2016, pp. 23-28. In this work, cork was chosen as template to produce novel ceria $\left(\mathrm{CeO}_{2}\right)$ ecoceramics, for applications in water splitting for $\mathrm{H} 2$ production via direct concentrated solar thermo chemical fuel production (TCFP). Energy and materials are currently two of the main focuses of Science and Technology, in particular due to environmental and supply concerns. The search for cheaper and more efficient energy production obviously involves the development of new and innovative materials. So, energy and materials are nowadays driving science and technology. The time when only a few materials such as steel, copper and concrete were the main components of energy technologies has long gone. In addition to new classes of materials, there is also a need to improve the physical and chemical characteristics of existing materials to improve the competitiveness of industrial materials production and to reduce their environmental footprint through better use of energy.

Issues such as the assessment of problems / risks in materials supply chains, especially critical raw materials, and the reliability of energy distribution, are now at the heart of the concerns. Concepts such as substitution and recycling are, of course, in the order of the day, to mitigate these risks and uncertainties. New energy technologies require significant and increasing quantities of raw materials / materials that in some cases are rare and in others they compete with other applications and may still be associated with geostrategic problems. So, among the key factors for the expansion of renewable energies are some strategic raw materials integrated in the materials destined

\author{
Volume 3 Issue I - 2019
}

\author{
Luís Gil \\ Coordinator of the Division of Materials \& Energy of the \\ Portuguese Materials Society, Portugal
}

\begin{abstract}
Correspondence: Luís Gil, Coordinator of the Division of Materials \& Energy of the Portuguese Materials Society, Divisão de Estudos Investigação e Renováveis, Av. 5 de Outubro, 208, 1069 - 203 Lisboa, Portugal,Tel +35I 217922 825, Email Luis.Gil@dgeg.pt
\end{abstract}

Received: February 22, 2019 | Published: February 27, 2019

to new energy technologies. Therefore, working / study groups should be established to identify and characterize the occurrences of these raw materials, as well as their associated economic activities, from a row perspective and incorporating the highest added value. These groups would have the objective of evaluating the potential of resources as a factor of economic development and strategic importance, determining the adoption of measures to promote their knowledge, valorization, promotion and dissemination, with a view to environmental sustainability and social responsibility, studying and defining the position that their country/region can assume in the world panorama. Dealing with these issues is e.g. the paper L. Gil, Research on materials and renewable energy, Science \& Technology of Materials, vol. 28, No. 2, 2016, pp. 124-129. Innovative materials having increased functionalities can improve energy productivity and transfer, enabling energy savings and new processes of sustainable energy production. For example, impressive breakthroughs are taking place for electricity generation, mainly in the field of solar and fuel cells.

Examples of energy materials are more durable materials in hightemperature environments with increased service life. Other materials as advanced composites, special polymeric materials, special metallic alloys and hybrid materials can improve the performance of equipment. Global economy is predicted to increase which is likely to result in increased energy demands. Raw materials are fundamental to the economy, and they are essential for maintaining and improving people's quality of life. There is a growth in the number of materials used across products and supply chains have become more complex. A comprehensive text also related to these subjects was published in the SPM Newsletter N ${ }^{\circ} 7$ Apr/Jun 2016, entitled "Research on Materials and Energy" as follows (translation). New materials are a central area of development in this field and are essential to new energy technologies, notably in terms of increased performance, reduced costs and longer life. For example, solar panels of various types, turbines propellers blades, components of wave energies systems, among others, all depend on advanced materials and the improvement of their characteristics. To see the importance of materials in the area of energy, let us look at the data of a major European initiative, EMIRI - Energy Industrial Materials Research Initiative:

I. $€ 4$ billion in sales of advanced energy materials.

II. $€ 400$ million of investment in advanced materials for energy.

III. $>20000$ direct jobs in the production of advanced materials for energy.

IV. $>4000$ researchers related to advanced materials for energy. 
EMIRI has established an advanced materials research program for Low Carbon Energy, which is divided into 19 topics of four key components to support the European Strategic Energy Technology Plan (SET Plan). It should be also noted that a Materials Information System (MIS) was released that provides information related to the materials (supply chain, type and quantity of material by technology etc.) used in the SET Plan. SET-Plan identified 60 materials as vital, from which a list of eight critical metals was selected. Various advanced materials will be needed in sufficient quantities to modify / improve energy infrastructures, but it will take several years to move from the research step to the day-to-day use. A European Commission report (2012) says that the global market for advanced materials is expected to reach $€ 1100$ billion by 2050 , of which $€ 16$ billion, $€ 176$ billion, will be materials for energy applications. There is a problem related to the supply of rare earths used, for example, to the magnets of electric vehicles and wind turbines or to photovoltaic panels, as about $90 \%$ of the known reserves of these raw materials are in China.
So topics like replacement, reuse and recycling and even increased efficiency are the order of the day. Another area related to materials and renewable energy is the production and testing of these materials. For example, the study of the use of concentrated solar energy for the production of fullerenes, ceramic foams and others is known. Concluding, like mentioned before for cork, materials, in general, and energy are intrinsically related, and their relationship is increasing and became more and more strong. The new energy paradigm will not be possible without the role of materials.

\section{Acknowledgments}

None.

\section{Conflicts of interest}

Author declares that there is no conflicts of interest. 